\title{
Aromatic character of planar boron-based clusters revisited by ring current calculations
}

\author{
Hung Tan Pham, ${ }^{\text {a,b }}$ Kie Zen Lim, ${ }^{\mathrm{c}}$ Remco W. A. Havenith ${ }^{\mathrm{c}}$ and Minh Tho \\ Nguyen ${ }^{\mathrm{d}, *}$ \\ ${ }^{a}$ Computational Chemistry Research Group, Ton Duc Thang University, Ho Chi Minh City, Vietnam \\ ${ }^{\mathrm{b}}$ Faculty of Applied Sciences, Ton Duc Thang University, Ho Chi Minh City, Vietnam \\ ${ }^{\mathrm{c}}$ Theoretical Chemistry, Zernike Institute for Advanced Materials and Stratingh Institute for Chemistry, \\ University of Groningen, NL-9747 AG Groningen, The Netherlands and Ghent Quantum Chemistry \\ Group, Department of Inorganic and Physical Chemistry, Ghent University, Krijgslaan 281 (S3), B-9000 \\ Gent, Belgium \\ ${ }^{\mathrm{d}}$ Department of Chemistry, KU Leuven, Celestijnenlaan 200F, B-3001 Leuven, Belgium.
}

Abstract: The planarity of small boron-based clusters is the result of an interplay between geometry, electron delocalization, covalent bonding and stability. These compounds contain two different bonding patterns involving both $\sigma$ and $\pi$ delocalized bonds, and up to now, their aromaticity has been assigned mainly using the classical $(4 \mathrm{~N}+2)$ electron count for both types of electrons. In the present study, we reexplored the aromatic feature of different types of planar boron-based clusters making use of the ring current approach. The $\mathrm{B}_{3}{ }^{+-}, \mathrm{B}_{4}{ }^{2-}, \mathrm{B}_{5}{ }^{+/-}, \mathrm{B}_{6}, \mathrm{~B}_{7}{ }^{-}, \mathrm{B}_{8}{ }^{2-}$, $\mathrm{B}_{9}{ }^{-}, \mathrm{B}_{10}{ }^{2-}, \mathrm{B}_{11}{ }^{-}, \mathrm{B}_{12}, \mathrm{~B}_{13}{ }^{+}, \mathrm{B}_{14}{ }^{2-}$ and $\mathrm{B}_{16}{ }^{2-}$ are characterized by magnetic responses to be doubly $\sigma$ and $\pi$ aromatic species in which the $\pi$ aromaticity can be predicted using the $(4 \mathrm{~N}+2)$ electron count. The triply aromatic character of $\mathrm{B}_{12}$ and $\mathrm{B}_{13}{ }^{+}$is confirmed. The $\pi$ electrons of $\mathrm{B}_{18}{ }^{2-}, \mathrm{B}_{19}{ }^{-}$ and $\mathrm{B}_{20}{ }^{2-}$ obey the disk aromaticity rule with electronic configuration of $\left[1 \sigma^{2} 1 \pi^{4} 1 \delta^{4} 2 \sigma^{2}\right]$ rather than the $(4 \mathrm{~N}+2)$ count. The double aromaticity feature is observed for boron hydride cycles including $\mathrm{B} @ \mathrm{~B}_{5} \mathrm{H}_{5}{ }^{+}, \mathrm{Li}_{7} \mathrm{~B}_{5} \mathrm{H}_{5}$ and $\mathrm{M} @ \mathrm{~B}_{\mathrm{n}} \mathrm{H}_{\mathrm{n}}{ }^{\mathrm{q}}$ clusters from both the $(4 \mathrm{~N}+2)$ rule and ring

\footnotetext{
*Email: minh.nguyen@chem.kuleuven.be
} 
current maps. The double $\pi$ and $\sigma$ aromaticity in carbon-boron planar cycles $\mathrm{B}_{7} \mathrm{C}^{-}, \mathrm{B}_{8} \mathrm{C}, \mathrm{B}_{6} \mathrm{C}_{2}$, $\mathrm{B}_{9} \mathrm{C}^{-}, \mathrm{B}_{8} \mathrm{C}_{2}$ and $\mathrm{B}_{7} \mathrm{C}_{3}^{-}$is in conflict with the Hückel electron count. This is also the case for the ions $\mathrm{B}_{11} \mathrm{C}_{5}^{+/-}$whose ring current indicators suggest that they belong to the class of double aromaticity, in which the $\pi$ electrons obey the disk aromaticity characteristics. In many clusters, the classical electron count cannot be applied, and the magnetic responses of the electron density expressed in terms of the ring current provide us with a more consistent criterion for determining their aromatic character.

\section{Introduction}

Studies of atomic clusters brought a profound impact not only on the rational design of materials with tailored chemical properties, but also on the understanding of new types of chemical bonding. ${ }^{1}$ There are in general many differences between clusters and bulk structures. As an elemental cluster, the $\mathrm{B}_{12}$ icosahedron, which is a unit of stable allotropes of solid boron, turns out to be less stable than a planar isomer. The latter is in fact the global minimum of the $\mathrm{B}_{12}$. Previous studies emphasized that the energetically lowest-lying gas phase structures of pure boron clusters frequently include the planar (or quasi-planar), tubular (double ring, triple ring and multiple ring), bowl-shaped, and fullerene-like or cage forms. The planar or quasi-planar structures are the most favorable for neutral B clusters whose size is smaller than 20 atoms. ${ }^{2,3}$ The double ring form, being the simplest tubular structure, consists of two $\mathrm{B}_{\mathrm{m}}$ strings connected in anti-prism fashion, emerges as the ground state structure of the even sizes $B_{2 m}$ in the range of $2 \mathrm{~m}=20-26 .{ }^{4}$ In the neutral state, both $\mathrm{B}_{14}$ and $\mathrm{B}_{27}$ clusters have special characteristics. $\mathrm{B}_{14}$ was found to be a fullerene-type ${ }^{5}$ whereas $\mathrm{B}_{27}$ is a triple ring tube ${ }^{6}$ resulting from a superposition of three $\mathrm{B}_{9}$ strings in anti-prism motif. In the cationic state, a 3D structure already appears for $\mathrm{B}_{17}{ }^{+}{ }^{7}$ On the contrary, the planar and quasi-planar forms are global minima structures for anionic 
boron clusters up to the larger size of $\mathrm{B}_{27}{ }^{-6,8}$ The $\mathrm{B}_{30}$ is theoretically identified as a bowl-shaped structure which has a pentagonal hole and satisfies the motif of $\mathrm{B}_{\mathrm{n}} @ \mathrm{~B}_{2 \mathrm{n}} @ \mathrm{~B}_{3 \mathrm{n}}$ with $\mathrm{n}=5$. $^{9}$ The $\mathrm{B}_{32},{ }^{10} \mathrm{~B}_{35}{ }^{11}$ and $\mathrm{B}_{36}{ }^{12}$ clusters are also members of the bowl-shaped family. The bowl $\mathrm{B}_{32}$ contains in addition heptagonal holes. ${ }^{10}$ For boron fullerenes, several extensive investigations and careful predictions were reported ${ }^{13,14,15,16,17,18}$ on their geometrical and electronic structure, and bonding properties. The $\mathrm{B}_{40}$ fullerene, which was predicted by computations, ${ }^{12}$ and subsequently detected by experiment, ${ }^{19}$ exhibits four heptagonal and two hexagonal holes. The fullerene $\mathrm{B}_{38}$ containing four hexagonal holes was found to be lowest-lying isomer, which is however nearly degenerate with a quasi-planar structure. ${ }^{20}$ While the $\mathrm{B}_{42}$ is a triple ring consisting of three fourteen atom strings, ${ }^{12}$ the $\mathrm{B}_{44}$ cluster has a cage-like structure containing two hexagonal, two heptagonal and two nonagonal holes. ${ }^{21}$ The $\mathrm{B}_{42}{ }^{+}$cation was found to be stable in an aromatic cage containing octagonal holes. ${ }^{22}$ The presence of octagonal and nonagonal holes, which is a remarkable and unprecedented finding, points out that the growth mechanism of boron clusters is still far from fully understood.

In view of such a complexity of the structures of boron clusters, different theoretical models have been proposed to establish the interplay between thermodynamic stability and geometrical feature. The planar shape of small boron clusters tends to be a frequent target for application of the classical $(4 \mathrm{~N}+2)$ Hückel rule for the aromaticity of their $\pi$ electrons, and some successes were recorded. ${ }^{8}$ The $(4 \mathrm{~N}+2)$ electron rule was originally proposed to account for the $\pi$ electron systems of conjugated cyclic hydrocarbons. It has recently been applied to the delocalized $\sigma$ electron systems. However, many planar boron clusters that have "ring-in-ring" type of structure including the anions $\mathrm{B}_{18}{ }^{2-}, \mathrm{B}_{19}{ }^{-}$and $\mathrm{B}_{20}{ }^{2-},{ }^{9,23}$ do not follow the Hückel electron count, irrespective of the electron type. These clusters have in fact diatropic magnetic response, 
indicating an aromatic character according to magnetic criteria, even though they each have $4 \mathrm{~N}$ electrons (which is expected to produce a paratropic ring current according to the Hückel electron count).

Based on a model of a particle moving in a circular box, the concept of disk aromaticity was introduced and can well reproduce the molecular orbital (MO) characteristics of the dianion $\mathrm{B}_{20}{ }^{2-}{ }^{23}$ This model has successfully been applied to poly-heterocyclic compounds. ${ }^{24}$ For tubular boron clusters, the hollow cylinder model (HCM), which is based on the wavefunction of a particle in a hollow cylinder box, excellently reproduces the MO pattern of tubular forms including the $\mathrm{B}_{2 \mathrm{~m}}$ double ring and $\mathrm{B}_{3 \mathrm{k}}$ triple ring structures. ${ }^{6,25}$ The HCM gives a consistent result with that obtained from ring current calculations. Therefore, they are classified as aromatic species but do not obey any classical electron count.

The aromatic character of smaller planar boron clusters has extensively been investigated in previous theoretical studies, and some contrasting conclusions have been drawn. On the basis of topological resonance energies (TRE), planar boron clusters were presented as highly aromatic species with large TRE values, even when they have $4 \mathrm{~N} \pi$ electrons. ${ }^{26}$ An earlier MO and NBO analysis ${ }^{27}$ suggested that the $\sigma$ electrons cannot be ignored, and the aromatic property of boron clusters can basically be assigned by using the classical $(4 \mathrm{~N}+2)$ electron count for both systems of $\pi$ and $\sigma$ electrons. The viewpoint that the aromatic feature of boron clusters should include $\sigma$ electrons, beside $\pi$ electrons, was further supported ${ }^{23}$ by an analysis of their electron localization function (ELF). The latter study demonstrated that $\sigma$ electrons are also highly delocalized and possess a different localization domain pattern with respect to $\pi$ electrons. ${ }^{28}$ These studies showed clearly that the consideration of $\sigma$ and $\pi$ orbital contributions to the molecular aromaticity is highly important to understand the interplay between geometry, aromatic property 
and stability of boron clusters.

In view of such conflicting characterizations obtained from different indicators, we set out to reinvestigate the aromatic features of small boron cluster using the magnetic responses obtained from ring current calculations. The ring current method provides us with an efficient tool to rationalize the aromaticity of clusters in both planar $2 \mathrm{D}^{29,30,31,32,33}$ and cage $3 \mathrm{D}^{34}$ structures. The advantage of this approach lies in the fact that the MO contributions to the total ring current maps can clearly be established, and consequently, the aromatic nature of $\sigma$ and $\pi$ electrons can separately be explored. We now attempt to obtain a comprehensive understanding on the aromatic feature of boron-based clusters, and in particular the feature of their $\sigma$ electrons. The present study thus devotes to a systematic analysis of the electron distribution of the planar $B_{n}{ }^{q}$ clusters with the size $n=3-20$ and the charge $q=-2,-1,0$ and 1 , using the ring current technique. In addition, some planar mixed B-C cyclic clusters, in which the $\mathrm{C}$ atom tends to avoid a high coordination position ${ }^{35,36,37}$ are examined. Other types of planar boron cycles are also considered including the $\mathrm{B} @ \mathrm{~B}_{5} \mathrm{H}_{5}{ }^{+}$and $\mathrm{B}_{5} \mathrm{H}_{5} \mathrm{Li}_{7}{ }^{+}$clusters, as well as some transition metal doped clusters $\mathrm{M} @ \mathrm{~B}_{\mathrm{n}} \mathrm{H}_{\mathrm{n}}{ }^{\mathrm{q}}$ with the metal $\mathrm{M}=\mathrm{Cr}, \mathrm{Mn}, \mathrm{Fe}$ and Co, and the charge being $\mathrm{q}=-2,-1$, 0 and 1. In the latter species, the metal M occupies a central position. ${ }^{38,39}$ The aromaticity of the latter clusters was previously rationalized on the basis of the $(4 \mathrm{~N}+2)$ Hückel rule only for their $\pi$ electrons. For each species considered, we perform the magnetically induced ring current induced not only from all electrons, but also from both sets of $\sigma$ and $\pi$ electrons.

\section{Computational Methods}

The global energy minimum geometries of the clusters $\mathrm{B}_{\mathrm{n}}{ }^{\mathrm{q}}$ (refs. 2,7,8), $\mathrm{B}_{\mathrm{n}} \mathrm{C}_{\mathrm{m}}$ (refs. 35,36,37), $\mathrm{M} @ \mathrm{~B}_{\mathrm{n}} \mathrm{H}_{\mathrm{n}}{ }^{\mathrm{q}}$ (refs.38,39), $\mathrm{B} @ \mathrm{~B}_{5} \mathrm{H}_{5}{ }^{+}$(ref. 40) and $\mathrm{B}_{5} \mathrm{H}_{5} \mathrm{Li}_{7}{ }^{+}$(ref. 41) are obtained from previous investigations. These structures are reoptimized using density functional theory (DFT) 
with the hybrid functional TPSSh in conjunction with the $6-311+\mathrm{g}(\mathrm{d})$ basis set. ${ }^{42}$ All geometry optimizations are carried out using the Gaussian 09 package. ${ }^{43}$ The ring current maps, ${ }^{44,45}$ along with the ipsocentric model, ${ }^{46,47}$ are calculated using DFT with the B3LYP functional and The 6$311 \mathrm{G}(\mathrm{d})$ basis set is employed throughout. Calculations on the magnetic responses are carried out using the CTOCD-DZ method ${ }^{45}$ implemented in the SYSMO program, ${ }^{48,49}$ which is connected to the GAMESS-UK package. ${ }^{50}$ In each current density map, the contour and shading show the modulus of induced current density and arrows display its projection on the plotting plane, which is also the corresponding molecular plane. As for a convention, anticlockwise and clockwise circulations correspond to diatropic and paratropic currents, respectively. A diatropic current density corresponds to an aromatic character whereas a paratropic current indicates an anti-aromaticity.

\section{Results and Discussion}

\subsection{The bare boron clusters}

In this section, we first analyze the electron distribution of the small pure boron clusters in different charge states. Their electronic feature was studied in previous studies. ${ }^{2,3,4}$ Here, only the clusters having a closed-shell electronic structure are considered. To simplify the presentation of data, all the Schemes 1-7 describing the geometries of clusters are displayed in the Supplementary Information (SI) file.

$\mathbf{B}_{3}{ }^{+}$and $\mathbf{B}_{3}{ }^{-}$. For the $\mathrm{B}_{3}{ }^{+}$and $\mathrm{B}_{3}{ }^{-}$ions, the canonical $\mathrm{MO}$ analysis illustrates that they satisfy the classical $(4 \mathrm{~N}+2)$ count with $\mathrm{N}=0$ for $\pi$ electrons, whereas only the anion $\mathrm{B}_{3}{ }^{-}$is $\sigma$-aromatic with two extra $\sigma$ electrons. ${ }^{7,27}$ As a consequence, $\mathrm{B}_{3}{ }^{-}$is doubly aromatic, and $\mathrm{B}_{3}{ }^{+}$is only $\pi$-aromaticity and non- $\sigma$-aromaticity with respect to the $(4 \mathrm{~N}+2)$ count. As given in Figure 1 , the $\sigma$ electrons of $\mathrm{B}_{3}{ }^{-}$and $\mathrm{B}_{3}{ }^{+}$produce the diatropic current indicating an aromatic feature. Diatropic currents are 
observed in the $\pi$-orbital maps of both $\mathrm{B}_{3}{ }^{-}$and $\mathrm{B}_{3}{ }^{+}$. Recently, the compounds containing $\mathrm{B}_{3}{ }^{+}$ cycle have been synthesized including $\left[\mathrm{B}_{3}(\mathrm{NN})_{3}\right]^{+}$and $\left[\mathrm{B}_{3}(\mathrm{CO})_{3}\right]^{+}$and subsequent analysis on aromaticity based on CMO and NICS calculations shows that $\mathrm{B}_{3}{ }^{+}$is only $\pi$ aromatic. ${ }^{51}$

In order to understand further on the $\sigma$-aromaticity of $\mathrm{B}_{3}{ }^{+}$, the possible electronic transitions are computed and illustrated in Figure S1. This cation possesses six $\sigma$ and two $\pi$ valence electrons. The four corresponding orbitals are basically three-center-two-electron orbitals. In $D_{3 \mathrm{~h}}$ symmetry, the $\sigma$-current density is raised by the vertical excitation from the HOMO-1,1' (E' symmetry) to the LUMO+1,1' (E' symmetry), and is under the selection rule of in-plane translations of $\mathrm{x}, \mathrm{y}$-axis, where $\Gamma(\mathrm{Txy})=\mathrm{E}^{\prime}=\mathrm{E}^{\prime} \mathrm{x} \mathrm{E}^{\prime}$. The vertical excitation from the HOMO ( $\mathrm{A}_{2}$ " symmetry) to the LUMO-2,2' (E" symmetry), which is under the selection rule of in-plane translations of $\mathrm{x}, \mathrm{y}$-axis where $\Gamma\left(\mathrm{T}_{\mathrm{xy}}\right)=\mathrm{E}^{\prime}=\mathrm{A}_{2}{ }^{\prime \prime} \mathrm{x} \mathrm{E}^{\prime \prime}$, produces the $\pi$ ring current map. Our ring current calculations show that $\mathrm{B}_{3}{ }^{+}$is $\sigma$ aromatic which is contributed by HOMO-1,1'. The previous analysis ${ }^{27,28}$ on $\mathrm{B}_{3}{ }^{+}$show that HOMO-1,1' are contributed mainly by $2 \mathrm{~s} \mathrm{AO}$ of $\mathrm{B}$ and these MOs are 3c-2e bonds, which is delocalized. On the electron count respective, the HOMO-1,1' and HOMO-2 provide $6 \sigma$ electrons, which satisfies the $(4 \mathrm{~N}+2)$ count with $\mathrm{N}=1$, therefore the $\mathrm{B}_{3}{ }^{+}$is $\sigma$ aromatic. Thus, from a magnetic viewpoint, both anionic and cationic trimers are doubly $\pi$ and $\sigma$ aromatic.

$\mathbf{B}_{4}{ }^{2+}$ and $\mathbf{B}_{4}{ }^{2-}$. As both dianions $\mathrm{B}_{4}{ }^{2-}$ and $\mathrm{Al}_{4}{ }^{2-}$ have a similar valence electron configuration, their electronic properties are expected to be similar. However, the ring current maps emphasize a sharp difference in their bonding. In the aluminum tetramer $\mathrm{Al}_{4}^{2-}$, although both $\mathrm{MCI}$ and $\operatorname{NICS}(0)$ results pointed out that the $\pi$ delocalization is slightly larger than that of the $\sigma$ counterpart, ${ }^{52}$ ring current calculations illustrate that $\pi$ electrons have an insignificant contribution to the ring current. ${ }^{53,54,55}$ Figure 1 shows a diatropic current density for $\pi$ electrons 
of the boron counterpart $\mathrm{B}_{4}{ }^{2-}$. As a result, the $\mathrm{B}_{4}{ }^{2-}$ dianion is $\pi$ aromatic while the isovalent $\mathrm{Al}_{4}{ }^{2-}$ is not, according to the magnetic criteria. No $\pi$ ring current can be detected for the dication $\mathrm{B}_{4}{ }^{2+}$, simply due to the fact that the $\pi$-orbital is empty. For $\sigma$ electron systems, both $\mathrm{B}_{4}{ }^{2-}$ and $\mathrm{B}_{4}{ }^{2+}$ ions show strongly diatropic currents, in such a way that they can be regarded as $\sigma$ aromatic. Overall, although it is isovalent to $\mathrm{Al}_{4}{ }^{2-}$, the dianion $\mathrm{B}_{4}{ }^{2-}$ is doubly $\sigma$ and $\pi$ aromatic rather than a sole $\sigma$ aromatic species. The dication $\mathrm{B}_{4}{ }^{2+}$ is only an $\sigma$ aromatic ring.

$\mathbf{B}_{5}{ }^{+}$and $\mathbf{B}_{5}{ }^{-}$. For the pentameric cation $\mathrm{B}_{5}{ }^{+}$, the distorted pentagon $\left({ }^{1} \mathrm{~A}_{1}, C_{2 \mathrm{v}}\right)$ is the ground state. ${ }^{7}$ From the CMOs, $\mathrm{B}_{5}{ }^{+}$is doubly aromatic with two delocalized $\sigma$ and two delocalized $\pi$ electrons. ${ }^{27}$ The $\pi$ and $\sigma$ current density maps of $\mathrm{B}_{5}{ }^{+}$displayed in Figure 2 contain diatropic flows. Although the planar $\mathrm{B}_{5}{ }^{-}$anion has four $\sigma$ and two $\pi$-electrons, ${ }^{3,27}$ the corresponding diatropic current density maps are observed for both $\pi$ and $\sigma$ orbitals in the magnetic response. Accordingly, the anion $\mathrm{B}_{5}{ }^{-}$belongs to the class of double $\sigma$ and $\pi$ aromaticity.

$\mathbf{B}_{6}{ }^{2-}$ and $\mathbf{B}_{6}$. The pentagonal pyramid $\left({ }^{1} \mathrm{~A}_{1}, C_{5 \mathrm{v}}\right) \mathrm{B}_{6}$ structure was predicted as the ground state of the $\mathrm{B}_{6}$ cluster (Scheme 1 of SI). ${ }^{3}$ Previous analysis pointed out that the neutral $\mathrm{B}_{6}$ possesses two delocalized $\pi$ and six delocalized $\sigma$ electrons (Schemes 1 and 2), therefore this structure is predicted to be doubly aromatic according to the $(4 \mathrm{~N}+2)$ count. $^{27}$ In term of magnetic response, $\sigma$ electrons induce a strongly diatropic ring current in the $\mathrm{B}_{5}$ plane of the $\mathrm{B}_{6}$ cluster (Figure 2). On the contrary, their $\pi$ electrons (HOMO-3, Scheme 2) are found to be inactive in the magnetic response. In other words, the total ring current within the molecular plane of the neutral $\mathrm{B}_{6}$ cluster is dominated by $\sigma$ orbitals. Overall, ring current calculations illustrate that the neutral $\mathrm{B}_{6}$ $\left(C_{5 \mathrm{v}}\right)$ is $\sigma$ aromatic, in agreement with the $(4 \mathrm{~N}+2)$ electron count.

Addition of two extra electrons to $\mathrm{B}_{6}$ gives rise to a planar dianion $\mathrm{B}_{6}{ }^{2-}$ (Scheme 1 ) which consists of a nearly square $\mathrm{B}_{4}$ core unit (Scheme 1). Previous topology resonance energy (TRE) 
computations ${ }^{26}$ suggested that the dianion $\mathrm{B}_{6}{ }^{2-}$ is highly aromatic. However, the stability of $\mathrm{B}_{6}{ }^{2-}$ was explained by MO analysis as the result of a combination of two aromatic $\mathrm{B}_{3}{ }^{-}$islands, ${ }^{27}$ and such a way of explaining is not consistent with the ring current results that indicate the electrons mainly move around the $\mathrm{B}_{4}$ ring. Previous ring current computations ${ }^{56}$ identified the $\mathrm{B}_{6}{ }^{2-}$ cluster as $\pi$ anti-aromatic. Our results displayed in Figure 2 concur with this, and suggest in addition that in both aromatic and anti-aromatic species, the electrons are effectively delocalized, but the difference in the numbers of electron leads to a different feature.

$\mathbf{B}_{7}^{-}$. A previous $\mathrm{CMO}$ analysis on $\left({ }^{1} \mathrm{~A}_{1}, C_{2 \mathrm{v}}\right) \mathrm{B}_{7}{ }^{-}$indicated that this ion has six delocalized $\sigma$ and four delocalized $\pi$ electrons. As a result, $\mathrm{B}_{7}{ }^{-}$was viewed as a $\pi$ anti-aromatic and $\sigma$ aromatic species. ${ }^{27}$ Current density calculations give however a less clear-cut picture. Figure S1 (SI) suggests that the $\pi$ orbitals of the $\mathrm{B}_{7}^{-}\left({ }^{1} \mathrm{~A}_{1}\right)$ induce a paratropic current density, whereas the $\sigma$ electrons generate weakly diatropic ring currents over the central $\mathrm{B}$ atom and the $\mathrm{B}_{6}$ ring, but stronger paratropic current around each atom of the six-membered ring (Figure 3). This is apparently similar to the results of $\mathrm{CMO}$ analysis but the total current density, as calculated for all electrons, give rise to a strongly paratropic current density, due to $\pi$ electron contributions. Furthermore, in $C_{2 v}$ point group symmetry, the z-axis in plane rotation, $\mathrm{R}_{\mathrm{z}}$ has $\mathrm{A}_{2}$ symmetry and the $\mathrm{x}$-axis in-plane translation has $\mathrm{B}_{1}$ symmetry. As shown in Figure S2 (SI), the vertical excitation from HOMO ( $\mathrm{B}_{2}$ symmetry) to LUMO ( $\mathrm{B}_{1}$ symmetry) is under the selection rule of inplane rotational $\mathrm{R}_{\mathrm{z}}$, where $\Gamma\left(\mathrm{R}_{\mathrm{z}}\right)=\mathrm{A}_{2}=\mathrm{B}_{2} \mathrm{x} \mathrm{B}_{1}$. There are two significant $\mathrm{x}$-axis in-plane translations from HOMO to LUMO. The vertical excitations from HOMO ( $\mathrm{B}_{2}$ symmetry) to LUMO+4 (A2 symmetry) and HOMO-5 (A1 symmetry) to LUMO ( $\mathrm{B}_{1}$ symmetry) are under the selection rule of in-plane translations of $\mathrm{x}$-axis, where $\Gamma\left(\mathrm{T}_{\mathrm{x}}\right)=\mathrm{B}_{1}=\mathrm{B}_{2} \mathrm{x} \mathrm{A}_{2}$ and $\Gamma\left(\mathrm{T}_{\mathrm{x}}\right)=\mathrm{B}_{2}=\mathrm{A}_{1} \mathrm{x}$ $\mathrm{B}_{1}$, respectively. The $\mathrm{B}_{7}^{-}\left({ }^{1} \mathrm{~A}_{1} C_{2 \mathrm{v}}\right)$ structure shows a small energy gap for the rotational 
transition from $\pi$ occupied orbital to $\pi$ unoccupied orbital (Figure S2). This means that rotational transitions tend to be favoured over translational transitions. Thus, the $\mathrm{B} 7$ anion is of paratropic nature, and thereby the singlet $\mathrm{B}_{7}^{-}\left({ }^{1} \mathrm{~A}_{1}, C_{2 \mathrm{v}}\right)$ can be regarded as anti-aromatic.

$\mathbf{B}_{8}, \mathbf{B}_{8}{ }^{2-}$ and $\mathbf{B}_{9}{ }^{-}$. The ring current maps of $\mathrm{B}_{8}, \mathrm{~B}_{8}{ }^{2-}$ and $\mathrm{B}_{9}{ }^{-}$are presented in Figure S2 of SI file. Our results are highly consistent to previous investigation of Fowler et. al. ${ }^{45}$ in which both $\mathrm{B}_{8}{ }^{2-}$ and $\mathrm{B}_{9}{ }^{-}$clusters are aromatic. For these species, the ring current calculations lend a support for the $(4 \mathrm{~N}+2)$ electron count.

$\mathbf{B}_{10}{ }^{2-}$ and $\mathbf{B}_{11}{ }^{-}$. Previous calculations indicated that the most stable isomer of the neutral $\mathrm{B}_{10}$ cluster has a quasi-planar form. ${ }^{3}$ A CMO analysis ${ }^{27}$ pointed out that neutral $\mathrm{B}_{10}$ satisfies the Hückel rule with six $\pi$ and six $\sigma$ electrons, in such a way that $\mathrm{B}_{10}$ is considered as being doubly aromatic. As the LUMO of $\mathrm{B}_{10}$ is also a delocalized $\sigma^{*} \mathrm{MO}$, the planar dianion $\mathrm{B}_{10}{ }^{2-}$ can be predicted to be $\sigma$ anti-aromatic with eight electrons, whereas the $\pi$ MOs maintain their characteristic aromaticity with six electrons. To consider this point, we add two electrons to $\mathrm{B}_{10}$ and then geometrically optimize the dianion $\mathrm{B}_{10}{ }^{2-}$ using the TPSSh $/ 6-311+\mathrm{g}(\mathrm{d})$ method. However, the $\sigma$ ring current of the dianion $\mathrm{B}_{10}{ }^{2-}$ turns out to be diatropic (Figure 3), thus suggesting an aromatic character. As expected, the $\pi$ electrons of $\mathrm{B}_{10}{ }^{2-}$ yield a diatropic current density. For a completed understanding on magnetic response of $\mathrm{B}_{10}{ }^{2-}$ clusters, the possible transitions are established in Figure $\mathrm{S} 3(\mathrm{SI})$. The excitation from HOMO-8 to LUMO+1 is under the selection rule of in-plane rotational $R_{z}$, where $\Gamma\left(R_{z}\right)=A_{2}=A_{1} \times A_{2}$. The excitation from HOMO-4 to LUMO is under the selection rule of in-plane translation in $\mathrm{x}$-axis $\mathrm{T}_{\mathrm{x}}$ where $\Gamma\left(\mathrm{T}_{\mathrm{x}}\right)=$ $\mathrm{B}_{1}=\mathrm{B}_{1} \times \mathrm{A}_{1}$. The excitation from HOMO-4 to LUMO+1 is under the selection rule of in-plane translation in y-axis, $\mathrm{T}_{\mathrm{y}}$ where $\Gamma\left(\mathrm{T}_{\mathrm{x}}\right)=\mathrm{B}_{2}=\mathrm{B}_{1} \times \mathrm{A}_{2}$. The $\mathrm{B}_{10}{ }^{2-}$ has the smaller energy gap of $\pi$ occupied orbital $-\pi$ unoccupied orbital translation transition in $\mathrm{x}$-direction than the rotational 
transition. Thus, as the tendency for translational transition is greater, the planar $\mathrm{B}_{10}{ }^{2-}$ dianion is also aromatic.

Similarly, an electronic structure analysis shows that the global minimum of the anion $\mathrm{B}_{11}{ }^{-}$ has six $\pi$ electrons and eight $\sigma$ electrons. However, Zubarev et al. ${ }^{27}$ considered that the delocalized $\sigma$ electrons of $\mathrm{B}_{11}{ }^{-}$should be similar to that of the dianion $\mathrm{B}_{6}{ }^{2-}$ in that there is combination of some local $\sigma$ aromatic character. As given in Figure 3, the $\pi$ ring current density of $\mathrm{B}_{11}{ }^{-}$is of diatropic nature, and thereby leads to a $\pi$ aromatic character. The $\sigma$ electrons of $\mathrm{B}_{11^{-}}{ }^{-}$ produce a more complicated ring current pattern, namely a weakly diatropic ring current along the perimeter, and a paratropic current around the boron centers (Figure 3). However, the total ring current remains strongly diatropic. Overall, both $\mathrm{B}_{10}{ }^{2-}$ and $\mathrm{B}_{11}{ }^{-}$clusters belong to the class of double $\sigma$ and $\pi$ aromaticity according to magnetic criteria, even though each contains eight $\sigma$ electrons.

$\mathbf{B}_{12}$ and $\mathbf{B}_{13}{ }^{+}$. Previous investigations indicated that the planar $\mathrm{B}_{12}$ and $\mathrm{B}_{13}{ }^{+}$clusters (Scheme 5 of SI file) are highly stable, even though the $\mathrm{B}_{12}$ icosahedron is a structural unit to form various kinds of boron morphologies. ${ }^{3}$ Each cluster is composed of an inner $B_{3}$ ring surrounded by an outer $\mathrm{B}_{9}$ or $\mathrm{B}_{10}$ ring. The $\sigma$ as well as the $\pi$ electrons of both $\mathrm{B}_{12}$ and $\mathrm{B}_{13}{ }^{+}$species satisfy the (4N +2 ) rule, thus they are viewed as double aromaticity. As seen in Figure 4, both $\sigma$ and $\pi$ orbitals of $\mathrm{B}_{12}$ and $\mathrm{B}_{13}{ }^{+}$contribute significantly to the diatropic ring current. The orbital contributions to the ring current maps of $\mathrm{B}_{12}$ and $\mathrm{B}_{13}{ }^{+}$are displayed in Figure S4 (SI). While the doubly degenerate HOMO is the main contributor to the $\sigma$ diatropic current density, the degenerate HOMO- 1 contribute significantly to the $\pi$ ring current as well. Kiran et al. ${ }^{57}$ considered both $\mathrm{B}_{12}$ and $\mathrm{B}_{13}{ }^{+}$clusters to have three delocalized systems involving six delocalized $\pi$, six delocalized $\sigma$ and six $\sigma$ (inner) electrons leading thus to a triple aromaticity. In the $\pi$ ring current maps, the 
contours are clear-cut and run over the whole molecule, whereas that of the $\sigma$ electrons concentrate not only along the outer $\mathrm{B}_{9}$ or $\mathrm{B}_{10}$ ring, but also more strongly around the perimeter of the inner $\mathrm{B}_{3}$ ring. In this context, the triply aromatic character of planar $\mathrm{B}_{12}$ and $\mathrm{B}_{13}{ }^{+}$clusters can be confirmed by magnetic properties.

The Elongated $\mathbf{B}_{14}{ }^{2-}$ and $\mathbf{B}_{16}{ }^{2-}$ clusters. The most stable form of the neutral $\mathrm{B}_{14}$ cluster is a fullerene, while the negatively charged states have again planar shapes ${ }^{5,8}$ (Scheme 6 of SI file). The dianion $\mathrm{B}_{14}{ }^{2-}$ has an elongated structure bearing ten $\pi$ and six $\sigma$ electrons, thus obeying the $(4 \mathrm{~N}+2)$ count rule. In terms of magnetic response, a diatropic current is observed for both sets of $\sigma$ and $\pi$ electrons of $\mathrm{B}_{14}^{2-}$ (Figure 5).

Other elongated boron clusters include the neutral $\mathrm{B}_{16}$ and the dianion $\mathrm{B}_{16}{ }^{2-}$ in which the $\mathrm{B}_{16}{ }^{2-}$ dianion was identified in a perfect planar shape. ${ }^{8} \mathrm{~A} \mathrm{CMO}$ analysis showed that $\mathrm{B}_{16}{ }^{2-}$ contains ten $\pi$ electrons distributed over five delocalized MOs. The ring current densities arising from $\pi$ orbitals of this dianion possesses a definitely diatropic feature (Figure 5). With sixteen delocalized $\sigma$ electrons, the dianion $\mathrm{B}_{16}{ }^{2-}$ could be viewed as anti-aromatic according to the (4N +2 ) electron count, but the corresponding ring current motion displayed in Figure 5 suggests a diatropic characteristic. Therefore, the dianion $\mathrm{B}_{16}{ }^{2-}$ can better be viewed as an $\sigma$ aromatic species. The possible electronic transitions of $\mathrm{B}_{16}{ }^{2-}$ are given in Figure S5 (SI). The vertical excitations from the HOMO ( $\mathrm{A}_{\mathrm{u}}$ symmetry) to the LUMO+2 ( $\mathrm{B}_{1 \mathrm{u}}$ symmetry), from the HOMO-6 $\left(\mathrm{B}_{1 \mathrm{u}}\right.$ symmetry) to the LUMO ( $\mathrm{B}_{2 \mathrm{~g}}$ symmetry) and from the HOMO-2 ( $\mathrm{B}_{3 \mathrm{~g}}$ symmetry) to the LUMO $+2\left(B_{1 u}\right.$ symmetry) are, under the selection rule, of the in-plane rotational $R_{z}$ and the inplane translationalof $x$-axis and y-axis, where $\Gamma\left(R_{z}\right)=B_{1 g}=A_{u} \times B_{1 u}, \Gamma\left(T_{x}\right)=B_{3 u}=B_{1 u} \times B_{2 g}$ and $\Gamma\left(\mathrm{T}_{\mathrm{y}}\right)=\mathrm{B}_{2 \mathrm{u}}=\mathrm{B}_{3 \mathrm{~g}} \times \mathrm{B}_{1 \mathrm{u}}$, respectively. Overall, both elongated boron clusters $\mathrm{B}_{14}{ }^{2-}$ and $\mathrm{B}_{16}{ }^{2-}$ can be classified as double $\sigma$ and $\pi$ aromaticity, in contrast with the $(4 \mathrm{~N}+2)$ count for the latter 
dianion.

$\mathrm{B}_{18}{ }^{2-}$ and $\mathrm{B}_{19}{ }^{-}$clusters: disk aromaticity. The $\mathrm{B}_{18}{ }^{2-}, \mathrm{B}_{19}{ }^{-}$and $\mathrm{B}_{20}{ }^{2-}$ clusters belong to the class of disk-aromatic species. ${ }^{8,58}$ Let us briefly mention the main characteristics of these clusters bearing a disk-shape. The shapes and the energy levels of the MOs of a related disk structure can be predicted using a model of a particle moving in a circular box. A planar or bowled system is classified as disk aromatic when its electrons fully occupy the lowest eigenstates of the model in the ascending ordering, namely $1 \sigma, 1 \pi, 1 \delta, 2 \sigma, 2 \pi, 1 \Phi, \ldots$ and so on. ${ }^{59}$ In previous studies, the planar dianion $\mathrm{B}_{20}{ }^{2-}$ cluster was identified as a disk aromatic species, involving both $\pi$ and $\sigma$ aromaticity using the ring current technique. ${ }^{60}$ In the case of $\mathrm{B}_{18}{ }^{2-}$ and $\mathrm{B}_{19}{ }^{-}$, they share the same orbital configuration of $\left[1 \sigma^{2} 1 \pi^{4} 1 \delta^{4} 2 \sigma^{2}\right]$ and they are accordingly classified as disk aromatic species. It is obvious that such numbers of electron involved do not obey the $(4 \mathrm{~N}+2)$ count.

Figure 6 illustrates the $\sigma, \pi$ and total current density maps of $\mathrm{B}_{18}{ }^{2-}$ and $\mathrm{B}_{19}{ }^{-}$. The orbitals having important contributions to their ring currents are shown in Figure S6 (SI). It is clear that the strongly diatropic ring currents are observed for both $\sigma$ and $\pi$ orbital sets. For $\mathrm{B}_{19^{-}}$, the doubly degenerate $1 \delta$ MOs (HOMO-1) are responsible for the current density of $\pi$ electrons. The $\pi$ ring current of the dianion $\mathrm{B}_{18}{ }^{2-}$ is basically determined by the non-degenerate HOMO-1, which corresponds to a $1 \delta$ orbital. The HOMO-3 which is an $\sigma-\mathrm{MO}$, has significant contributions to the $\sigma$ ring current of $\mathrm{B}_{18}{ }^{2-}$, and the diatropic $\sigma$ current density of $\mathrm{B}_{19}{ }^{-}$arises from the doubly degenerate HOMO-2 (Figure S6 of SI file).

\subsection{Aromaticity of the $\mathrm{B} @ \mathrm{~B}_{5} \mathrm{H}_{5}^{+}$and $\mathrm{Li}_{7} \mathrm{~B}_{5} \mathrm{H}_{5}{ }^{+}$clusters.}

In an attempt to extend the scope of the approach using ring current beyond the pure boron clusters, we consider here two boron hydride derivatives. The optimized geometries of these boron hydrides are depicted in Scheme 7 of the SI. Both ions are formed from the $\mathrm{B}_{5} \mathrm{H}_{5}{ }^{+}$unit, 
which is planar and highly symmetrical $\left(D_{5 \mathrm{~h}}\right)$ in its singlet lowest-lying ground state. In the $\mathrm{B}_{6} \mathrm{H}_{5}{ }^{+}$cation, the sixth $\mathrm{B}$ atom is added at the center of the pentagonal ring, thus giving rise to a planar cycle in which one $\mathrm{B}$ atom is surrounded by the planar cyclic $\mathrm{B}_{5} \mathrm{H}_{5}$ unit. ${ }^{40}$ The $\mathrm{Li}_{7} \mathrm{~B}_{5} \mathrm{H}_{5}{ }^{+}$ cation is also found to be stable in a symmetrical cyclic form, in which the $\mathrm{B}_{5} \mathrm{H}_{5}$ five-membered ring is capped by seven lithium atoms in the molecular plane and along the $\mathrm{C}_{5}$ axis. ${ }^{41}$ An $\mathrm{MO}$ analysis indicates that for both structures, the aromatic feature can be characterized either by two $\pi$ electrons $\left(\mathrm{B}_{6} \mathrm{H}_{5}{ }^{+}\right)$or six $\pi$ electrons $\left(\mathrm{Li}_{7} \mathrm{~B}_{5} \mathrm{H}_{5}{ }^{+}\right)$, thus satisfying the $(4 \mathrm{~N}+2)$ rule. The $\sigma, \pi$ and total current density maps in the molecular planes of both cations are presented in Figure 7. Strongly diatropic ring currents emerge from the $\pi$ electrons of both molecules. More interestingly, the delocalized $\sigma$ electrons also generate strongly diatropic current densities, thereby suggesting that both boron cycles $\mathrm{Li}_{7} \mathrm{~B}_{5} \mathrm{H}_{5}{ }^{+}$and $\mathrm{B} @ \mathrm{~B}_{5} \mathrm{H}_{5}{ }^{+}$can equally be classified into the family of $\sigma$ aromatic species.

To identify the main contributors, the total ring currents that are partitioned into contributions of individual orbitals, are carried out and summarized in Figure S7 of SI. For $\mathrm{Li}_{7} \mathrm{~B}_{5} \mathrm{H}_{5}{ }^{+}$, the degenerate HOMO turns out to be the main contributor to the $\pi$ ring current, whereas the degenerate HOMO-2 dominates the $\sigma$ aromaticity. In $\mathrm{B} @ \mathrm{~B}_{5} \mathrm{H}_{5}^{+}$, the non-degenerate HOMO-1 significantly contributes to the diatropic $\pi$ current density, and the degenerate HOMO produces the strongly diatropic $\sigma$ ring current maps. Both $\mathrm{Li}_{7} \mathrm{~B}_{5} \mathrm{H}_{5}{ }^{+}$and $\mathrm{B} @ \mathrm{~B}_{5} \mathrm{H}_{5}{ }^{+}$cyclic structures are doubly $\pi$ and $\sigma$ aromatic, even though they do not always follow the classical electron count.

\subsection{Planar metal cyclic $M @ B_{n} H_{n}{ }^{q}$ clusters, with metal $M=C r, M n, F e$ and $C o$ and charge} $q=-2,-1,0,1$ and $n=6,7$.

Recently, the transition metal doped $\mathrm{M} @ \mathrm{~B}_{\mathrm{n}} \mathrm{H}_{\mathrm{n}}{ }^{\mathrm{q}}$ cyclic planar geometrical motif in which the 
metal atom is located at the central position of a $\mathrm{B}_{\mathrm{n}} \mathrm{H}_{\mathrm{n}}$ cycle, was discovered using quantum chemical calculations. ${ }^{38,39}$ Previous studies reported that they have singlet ground state. ${ }^{38,39}$ In an attempt to understand their electronic behavior, we consider now some representative derivatives made with $\mathrm{M}=\mathrm{Co}, \mathrm{Fe}, \mathrm{Mn}$ and $\mathrm{Cr}, \mathrm{n}=6$ and 7 , and the net charge $\mathrm{q}=+1,0,-1$ and -2 . In all the resulting systems, the most stable form corresponds to a highly symmetrical and planar species belonging either to the $D_{6 \mathrm{~h}}$ or the $D_{7 \mathrm{~h}}$ point group. Here we consider only their singlet states, irrespective of their identity. An analysis of their MOs points out that each of the M@ $\mathrm{B}_{6} \mathrm{H}_{6}{ }^{\mathrm{q}}$ $\left(D_{6 \mathrm{~h}}\right)$ and $\mathrm{M} @ \mathrm{~B}_{7} \mathrm{H}_{7}{ }^{\mathrm{q}}\left(D_{7 \mathrm{~h}}\right)$ species possesses six $\pi$ electrons. The $\pi, \sigma$ and total current density maps of metallic boron cycles are displayed in Figure 8, and Figure S8 (SI). Both $\sigma$ and $\pi$ orbitals of the metallic hydrogenated boron cycles contribute to a diatropic ring current. As for a comprehensive understanding, the ring current contributions of each MO of $\mathrm{Fe} @ \mathrm{~B}_{7} \mathrm{H}_{7}$ and Fe@ $\mathrm{B}_{6} \mathrm{H}_{6}$ are carried out and given in Figure $\mathrm{S} 9$ and $\mathrm{S} 10$ of the SI file.

The doubly degenerate $\pi$ MO of both species Fe@ $\mathrm{B}_{7} \mathrm{H}_{7}$ and $\mathrm{Fe} @ \mathrm{~B}_{6} \mathrm{H}_{6}$, namely the HOMO3 , is found as the main contributor to the $\pi$ current. Each $\mathrm{MO}$ arises from a combination of the $3 d_{\mathrm{xz}}$ and $3 d_{\mathrm{yz}}$ orbitals of the metal $\mathrm{M}$ with the $2 p_{\mathrm{z}}$ orbitals located on the $\mathrm{B}$ atoms. Accordingly, the $\pi$ aromaticity plays a dominant role in the perfectly planar shape. Previous investigations on these clusters considered only $\pi$ electrons, ${ }^{38,39}$ but the $\sigma$ electrons of the boron rings also significantly participate to the molecular aromaticity. The $\sigma$ electrons of both metallic hydrogenated boron cycles consistently contribute to the diatropic current density (Figure S10, SI). It is clear that the degenerate HOMO-5 of either Fe@ $a \mathrm{~B}_{7} \mathrm{H}_{7}$ or $\mathrm{Fe} @ \mathrm{~B}_{6} \mathrm{H}_{6}$ is the result of a combination of the $3 d_{x y}$ and $3 d_{x 2-y 2}$ AOs of M with the HOMO-1 of the boron ring yielding three delocalized $\sigma$ MOs. Although this formally satisfies the $(4 \mathrm{~N}+2)$ electron count, the HOMO-5 does not contribute to the total ring current, as it gives rise to localized, islands of current around 
the nuclei. The HOMO-1 is inactive in the magnetic response. The degenerate HOMO-2, which corresponds to the B-B connections, makes a dominant contribution to the $\sigma$ ring current for $\mathrm{Fe} @ \mathrm{~B}_{7} \mathrm{H}_{7}$. Thus, the $3 d$ - orbitals of the transition metal do not significantly influence much the aromatic property of $\sigma$ electrons. A similar pattern also holds for the Fe $@ \mathrm{~B}_{6} \mathrm{H}_{6}$ species.

\subsection{The carbon doped boron clusters $B_{n} C_{m}$}

The $\mathrm{B}_{7} \mathrm{C}^{-}$and $\mathrm{B}_{6} \mathrm{C}_{2}{ }^{-}$clusters have the most stable cyclic structure, in which the $\mathrm{C}$ atom does not occupy a central position. ${ }^{35}$ On the electronic aspect, both $\mathrm{B}_{7} \mathrm{C}^{-}$and neutral $\mathrm{B}_{6} \mathrm{C}_{2}$ cycles are isoelectronic with the $\mathrm{B}_{8}{ }^{2-}$ cycle examined above. For a comparison to $\mathrm{B}_{8}{ }^{2-}$ the neutral $\mathrm{B}_{6} \mathrm{C}_{2}$ cycle is optimized using the geometry of the anion $\mathrm{B}_{6} \mathrm{C}_{2}^{-}$, and as a result, $\mathrm{CMO}$ analysis of $\mathrm{B}_{7} \mathrm{C}^{-}$and $\mathrm{B}_{6} \mathrm{C}_{2}$ structures also indicates a doubly aromatic feature involving six $\pi$ and six $\sigma$ electrons. Our purpose here is however not a search for the global minimum of this neutral $\mathrm{B}_{6} \mathrm{C}_{2}$. Ring current calculations give, as expected, a similar conclusion on the aromatic property of both planar $\mathrm{B}_{7} \mathrm{C}^{-}$ and $\mathrm{B}_{6} \mathrm{C}_{2}$ compounds. As demonstrated in Figure 9, a diatropic current density is observed for each of both sets of $\pi$ and $\sigma$ orbitals, thus supporting the $(4 \mathrm{~N}+2)$ count.

The $\mathrm{CB}_{8}$ cluster, which is isoelectronic with the anion $\mathrm{B}_{9}{ }^{-}$, also has a planar cyclic structure. $^{36,61}$ Similarly to $\mathrm{B}_{9}{ }^{-}, \mathrm{CB}_{8}$ is doubly aromatic as their $\pi$ and $\sigma$ electrons obey the $(4 \mathrm{~N}+2)$ rule with $N=1$. Such an aromatic character is now supported by the $\pi$ and $\sigma$ current densities that clearly display the diatropic feature (Figure 9). Both $\mathrm{B}_{9} \mathrm{C}^{-}$and $\mathrm{B}_{8} \mathrm{C}_{2}$ clusters were experimentally identified and theoretically shown to have each a slightly distorted (but nearly planar) cyclic form, in which one $\mathrm{B}$ atom occupies the central position. ${ }^{37}$ Either $\mathrm{B}_{9} \mathrm{C}^{-}$or $\mathrm{B}_{8} \mathrm{C}_{2}$ possesses six $\pi$ electrons, which is similar to the isoelectronic planar $\mathrm{B}_{10}{ }^{2-}$. In terms of magnetic response, the $\pi$ orbitals of $\mathrm{B}_{9} \mathrm{C}^{-}$or $\mathrm{B}_{8} \mathrm{C}_{2}$ contribute to diatropic current density. Similarly, the magnetic response of the $\sigma$ orbitals is strongly diatropic in nature, corresponding thus to $\sigma$ 
aromaticity (Figure $\mathrm{S} 11, \mathrm{SI}$ ). Either $\mathrm{B}_{8} \mathrm{C}_{2}{ }^{2-}$ or $\mathrm{B}_{7} \mathrm{C}_{3}{ }^{-}$possesses eight $\pi$ electrons, and they give rise to a paratropic $\pi$ ring current. On the contrary, a weakly diatropic contribution to the current is found from the set of $\sigma$ orbitals. In spite of such a conflicting aromatic character, the total ring current remains paratropic (Figure S11, SI).

On basis of the $(4 \mathrm{~N}+2)$ electron count, Schleyer and coworkers ${ }^{62}$ developed a way of designing the planar aromatic clusters based on C-B mixing. According to this prediction, the cation $\mathrm{C}_{5} \mathrm{~B}_{11}{ }^{+}$should be aromatic and the anion $\mathrm{C}_{5} \mathrm{~B}_{11}{ }^{-}$anti-aromatic. In other words, the $\pi$ ring current of the cation $\mathrm{C}_{5} \mathrm{~B}_{11}{ }^{+}$should be diatropic, and that of the anion $\mathrm{C}_{5} \mathrm{~B}_{11}{ }^{-}$paratropic. However, computations show that the cation $\mathrm{C}_{5} \mathrm{~B}_{11}{ }^{+}$appears to have both diatropic $\sigma$ and $\pi$ currents (Figure 10). As a consequence, the total ring current involving all $\sigma$ and $\pi$ orbitals also has a diatropic feature, even though they are not strong. Thus, this cation is confirmed to be doubly $\pi$ and $\sigma$ aromatic following the magnetic criteria. On the contrary, although the anion $\mathrm{C}_{5} \mathrm{~B}_{11}{ }^{-}$contains twelve delocalized $\pi$ electrons, which satisfy the $4 \mathrm{~N}$ count, its delocalized $\pi$ MOs yield a diatropic current density. Similarly, the $\sigma$ orbitals of $\mathrm{C}_{5} \mathrm{~B}_{11}{ }^{-}$contribute to a diatropic ring current. Therefore, the anion $\mathrm{C}_{5} \mathrm{~B}_{11}{ }^{-}$behaves as a doubly aromatic molecule rather than an antiaromatic one as simply suggested by the number of electrons.

The aromaticity of both ions $\mathrm{B}_{11} \mathrm{C}_{5}^{+/-}$can also be rationalized in terms of the disk aromaticity concept in which the $\pi$ electrons of $\mathrm{C}_{5} \mathrm{~B}_{11}{ }^{+}$and $\mathrm{C}_{5} \mathrm{~B}_{11}{ }^{-}$occupy the orbital configurations of $\left[(1 \sigma)^{2}(1 \pi)^{4}(1 \delta)^{4}\right]$ and $\left[(1 \sigma)^{2}(1 \pi)^{4}(1 \delta)^{4}(2 \sigma)^{2}\right]$, respectively. ${ }^{24}$ The magnetic responses lend a further support for the disk aromatic feature of the cation $\mathrm{C}_{5} \mathrm{~B}_{11}{ }^{+}$and anion $\mathrm{C}_{5} \mathrm{~B}_{11}{ }^{-}$.

\subsection{The electron count.}

It is obvious that the simplest way of predicting the aromaticity of a cyclic species is using 
the electron count in which the $(4 \mathrm{~N}+2)$ Hückel rule is the most popular for planar cyclic compounds. In the current situation, this classical rule draws a consistent prediction in the monocyclic structures including boron cyclic structure $\left(\mathrm{B}_{7}^{-}, \mathrm{B}_{8}{ }^{2-}, \mathrm{B}_{9}{ }^{-}\right)$, the hydrogenated boron cycles $\left(\mathrm{B} @ \mathrm{~B}_{5} \mathrm{H}_{5}{ }^{+}, \mathrm{Li}_{7} \mathrm{~B}_{5} \mathrm{H}_{5}\right.$ and $\mathrm{M} @ \mathrm{~B}_{\mathrm{n}} \mathrm{H}_{\mathrm{n}}{ }^{\mathrm{q}}$ clusters $)$ and the carbon-boron planar cycles $\left(\mathrm{B}_{7} \mathrm{C}^{-}\right.$, $\mathrm{B}_{8} \mathrm{C}, \mathrm{B}_{6} \mathrm{C}_{2}, \mathrm{~B}_{9} \mathrm{C}^{-}, \mathrm{B}_{8} \mathrm{C}_{2}$ and $\left.\mathrm{B}_{7} \mathrm{C}_{3}^{-}\right)$. For these systems, both $\pi$ and $\sigma$ electrons obey the $(4 \mathrm{~N}+2)$ count. In the case of the ring-in-ring structures involving $\mathrm{B}_{12}, \mathrm{~B}_{13}{ }^{+}, \mathrm{B}_{18}{ }^{2-}, \mathrm{B}_{19}{ }^{-}, \mathrm{B}_{20}{ }^{2-}, \mathrm{C}_{5} \mathrm{~B}_{11}{ }^{+}$and $\mathrm{C}_{5} \mathrm{~B}_{11}{ }^{-}$, the $(4 \mathrm{~N}+2)$ count is no longer valid, whereas the disk aromaticity count agrees well with the indication of ring currents. The $\mathrm{B}_{10}{ }^{2-}, \mathrm{B}_{11}{ }^{-}, \mathrm{B}_{14}{ }^{2-}$ and $\mathrm{B}_{16}{ }^{2-}$, which can be considered as fused structure of mono boron cycles, do not obey the $(4 \mathrm{~N}+2)$. As a result, the $(4 \mathrm{~N}+2)$ electron count is valid only in boron-based monocyclic structures. Overall, in a certain shape, a particular electronic population appears giving rise to an aromatic feature, and thereby enhancing its thermodynamic stability. There is however no general electron count for all types of boron-based clusters.

\section{Concluding Remarks}

In the present theoretical study, we revisited the aromaticity feature of various planar boronbased clusters using the magnetic ring current criteria. In all the clusters considered, the $\sigma$ electrons are identified to substantially contribute to the total ring current, which confer an aromatic or anti-aromatic character, irrespective of the classical $(4 \mathrm{~N}+2)$ electron count. This magnetic property firmly establishes the $\sigma$ aromaticity of the species considered. The aromatic characteristics of the species considered, according to both criteria, are summarized and compared in Table 1.

For bare boron clusters, from $\mathrm{B}_{3}{ }^{+/-}$to $\mathrm{B}_{16}{ }^{2-}$, the classical $(4 \mathrm{~N}+2)$ electron count is more consistent with the prediction of the magnetic responses of the $\pi$ electrons. The clusters $\mathrm{B}_{3}{ }^{+/}$, 
$\mathrm{B}_{4}{ }^{2-}, \mathrm{B}_{5}{ }^{+/-}, \mathrm{B}_{6}, \mathrm{~B}_{7}^{-}, \mathrm{B}_{8}{ }^{2-}, \mathrm{B}_{9}^{-}, \mathrm{B}_{10}{ }^{2-}, \mathrm{B}_{11}^{-}, \mathrm{B}_{12}, \mathrm{~B}_{13}{ }^{+}, \mathrm{B}_{14}{ }^{2-}$ and $\mathrm{B}_{16}{ }^{2-}$ are identified as doubly $\sigma$ and $\pi$ aromatic species, in which the $\pi$ aromaticity can be predicted using the $(4 \mathrm{~N}+2)$ electron count. In the case of $\mathrm{B}_{18}{ }^{2-}, \mathrm{B}_{19}{ }^{-}$and $\mathrm{B}_{20}{ }^{2-}$ anions possessing twelve $\pi$-electrons, the $(4 \mathrm{~N}+2)$ electron count is no longer valid, due to the fact that the corresponding $\pi$ electrons produce strongly diatropic current densities. They belong to the class of disk aromaticity with the electronic configuration of $\left[1 \sigma^{2} 1 \pi^{4} 1 \delta^{4} 2 \sigma^{2}\right]$.

The double aromaticity feature is again observed for hydrogenated boron cycles including the $\mathrm{B} @ \mathrm{~B}_{5} \mathrm{H}_{5}{ }^{+}, \mathrm{Li}_{7} \mathrm{~B}_{5} \mathrm{H}_{5}$ and $\mathrm{M} @ \mathrm{~B}_{\mathrm{n}} \mathrm{H}_{\mathrm{n}}{ }^{\mathrm{q}}$ clusters, according to both the $(4 \mathrm{~N}+2)$ rule and ring current indicator. Similarly, the sense of the induced ring currents and the $(4 \mathrm{~N}+2)$ electron count are consistent with each other indicating that the carbon-boron planar cycles $\mathrm{B}_{7} \mathrm{C}^{-}, \mathrm{B}_{8} \mathrm{C}$, $\mathrm{B}_{6} \mathrm{C}_{2}, \mathrm{~B}_{9} \mathrm{C}^{-}, \mathrm{B}_{8} \mathrm{C}_{2}$ and $\mathrm{B}_{7} \mathrm{C}_{3}^{-}$are doubly $\pi$ and $\sigma$ aromatic. For the $\mathrm{B}_{11} \mathrm{C}_{5}^{+/-}$clusters, the ring current indicator confirms that they are both disk aromatic species. Dependent on the size of the cluster considered, the aromaticity due to $\pi$ electrons can be predicted using the $(4 \mathrm{~N}+2)$ electron count, whereas the aromatic feature of $\sigma$-electrons turns out to be more complex, irrespective of the cluster size. Overall, the present study points out once more that, in many cases, the classical electron count cannot be applied, and the magnetic responses of the electron density, expressed in terms of ring currents, provide us with a more consistent criterion for determining the aromatic character of these clusters.

Acknowledgements: The authors are indebted to the KU Leuven Research Council (GOA and IDO programs) and the Flemish Fund for Scientific Research (FWO-Vlaanderen). We thank the Ton Duc Thang University (TDTU-DEMASTED) and Institute for Computational Science and 
Technology at Ho Chi Minh City (ICST) for support. We are grateful to Arnout Ceulemans and Athanasios Arvanitidis for illuminating discussion on the boron conundrum.

Supplementary Information. 
Table 1. The aromaticity and anti-aromaticity of the clusters considered assigned by the $(4 \mathrm{~N}+2)$ electron count and ring current map. $\mathrm{Ar}=$ aromatic and $\mathrm{Anti}-\mathrm{Ar}=$ anti-aromatic.

\begin{tabular}{|c|c|c|c|c|}
\hline \multirow{2}{*}{ Cluster } & \multicolumn{2}{|c|}{$(4 \mathrm{~N}+2)$ count } & \multicolumn{2}{|c|}{ Ring current } \\
\hline & $\sigma$ electrons & $\pi$ electrons & $\sigma$ electrons & $\pi$ electrons \\
\hline $\mathrm{B}_{3}^{+}$ & & $\mathrm{Ar}$ & $\mathrm{Ar}$ & $\mathrm{Ar}$ \\
\hline $\mathrm{B}_{3}^{-}$ & $\mathrm{Ar}$ & $\mathrm{Ar}$ & $\mathrm{Ar}$ & $\mathrm{Ar}$ \\
\hline $\mathrm{B}_{4}{ }^{2+}$ & $\mathrm{Ar}$ & & $\mathrm{Ar}$ & \\
\hline $\mathrm{B}_{4}{ }^{2-}$ & $\mathrm{Ar}$ & $\mathrm{Ar}$ & $\mathrm{Ar}$ & $\mathrm{Ar}$ \\
\hline $\mathrm{B}_{5}^{+}$ & $\mathrm{Ar}$ & $\mathrm{Ar}$ & $\mathrm{Ar}$ & $\mathrm{Ar}$ \\
\hline $\mathrm{B}_{5}^{-}$ & Anti-Ar & $\mathrm{Ar}$ & $\mathrm{Ar}$ & $\mathrm{Ar}$ \\
\hline $\mathrm{B}_{6}$ & $\mathrm{Ar}$ & $\mathrm{Ar}$ & $\mathrm{Ar}$ & No-Ar \\
\hline $\mathrm{B}_{6}{ }^{2-}$ & Anti-Ar & Anti-Ar & Anti-Ar & Anti-Ar \\
\hline $\mathrm{B}_{7}^{-}$ & $\mathrm{Ar}$ & Anti-Ar & $\mathrm{Ar}$ & Anti-Ar \\
\hline $\mathrm{B}_{8}\left(\mathrm{C}_{2 \mathrm{v}}\right)$ & $\mathrm{Ar}$ & Anti-Ar & $\mathrm{Ar}$ & Anti-Ar \\
\hline $\mathrm{B}_{8}{ }^{2-}$ & $\mathrm{Ar}$ & $\mathrm{Ar}$ & $\mathrm{Ar}$ & $\mathrm{Ar}$ \\
\hline $\mathrm{B}_{9}{ }^{-}$ & $\mathrm{Ar}$ & $\mathrm{Ar}$ & $\mathrm{Ar}$ & $\mathrm{Ar}$ \\
\hline $\mathrm{B}_{10}{ }^{2-}$ & Anti-Ar & $\mathrm{Ar}$ & $\mathrm{Ar}$ & $\mathrm{Ar}$ \\
\hline $\mathrm{B}_{11}^{-}$ & Anti-Ar & $\mathrm{Ar}$ & $\mathrm{Ar}$ & $\mathrm{Ar}$ \\
\hline $\mathrm{B}_{12}$ & $\mathrm{Ar}$ & $\mathrm{Ar}$ & $\mathrm{Ar}$ & $\mathrm{Ar}$ \\
\hline $\mathrm{B}_{13}{ }^{+}$ & $\mathrm{Ar}$ & $\mathrm{Ar}$ & $\mathrm{Ar}$ & $\mathrm{Ar}$ \\
\hline $\mathrm{B}_{14}^{2-}$ & $\mathrm{Ar}$ & $\mathrm{Ar}$ & $\mathrm{Ar}$ & $\mathrm{Ar}$ \\
\hline $\mathrm{B}_{16}^{2-}$ & $\mathrm{Ar}$ & Anti-Ar & $\mathrm{Ar}$ & $\mathrm{Ar}$ \\
\hline $\mathrm{B}_{18}{ }^{2-}$ & Anti-Ar & Anti-Ar & $\mathrm{Ar}$ & $\mathrm{Ar}$ \\
\hline $\mathrm{B}_{19^{-}}$ & Anti-Ar & Anti-Ar & $\mathrm{Ar}$ & $\mathrm{Ar}$ \\
\hline $\mathrm{B}_{6} \mathrm{H}_{5}^{+}$ & $\mathrm{Ar}$ & $\mathrm{Ar}$ & $\mathrm{Ar}$ & $\mathrm{Ar}$ \\
\hline $\mathrm{B}_{5} \mathrm{H}_{5} \mathrm{Li}_{7}^{+}$ & $\mathrm{Ar}$ & $\mathrm{Ar}$ & $\mathrm{Ar}$ & $\mathrm{Ar}$ \\
\hline $\mathrm{CoB}_{6} \mathrm{H}_{6}^{+}$ & $\mathrm{Ar}$ & $\mathrm{Ar}$ & $\mathrm{Ar}$ & $\mathrm{Ar}$ \\
\hline $\mathrm{FeB}_{6} \mathrm{H}_{6}$ & $\mathrm{Ar}$ & $\mathrm{Ar}$ & $\mathrm{Ar}$ & $\mathrm{Ar}$ \\
\hline $\mathrm{MnB}_{6} \mathrm{H}_{6}^{-}$ & $\mathrm{Ar}$ & $\mathrm{Ar}$ & $\mathrm{Ar}$ & $\mathrm{Ar}$ \\
\hline
\end{tabular}




\begin{tabular}{ccccc}
$\mathrm{CrB}_{6} \mathrm{H}_{6}^{2-}$ & $\mathrm{Ar}$ & $\mathrm{Ar}$ & $\mathrm{Ar}$ & $\mathrm{Ar}$ \\
$\mathrm{CoB}_{7} \mathrm{H}_{7}^{+}$ & $\mathrm{Ar}$ & $\mathrm{Ar}$ & $\mathrm{Ar}$ & $\mathrm{Ar}$ \\
$\mathrm{FeB}_{7} \mathrm{H}_{7}$ & $\mathrm{Ar}$ & $\mathrm{Ar}$ & $\mathrm{Ar}$ & $\mathrm{Ar}$ \\
$\mathrm{MnB}_{7} \mathrm{H}_{7}^{-}$ & $\mathrm{Ar}$ & $\mathrm{Ar}$ & $\mathrm{Ar}$ & $\mathrm{Ar}$ \\
$\mathrm{CrB}_{7} \mathrm{H}_{7}^{2-}$ & $\mathrm{Ar}$ & $\mathrm{Ar}$ & $\mathrm{Ar}$ & $\mathrm{Ar}$ \\
\hline $\mathrm{B}_{7} \mathrm{C}^{-}$ & $\mathrm{Ar}$ & $\mathrm{Ar}$ & $\mathrm{Ar}$ & $\mathrm{Ar}$ \\
$\mathrm{B}_{6} \mathrm{C}_{2}$ & $\mathrm{Ar}$ & $\mathrm{Ar}$ & $\mathrm{Ar}$ & $\mathrm{Ar}$ \\
$\mathrm{B}_{8} \mathrm{C}^{-2}$ & $\mathrm{Ar}$ & $\mathrm{Ar}$ & $\mathrm{Ar}$ & $\mathrm{Ar}$ \\
$\mathrm{B}_{9} \mathrm{C}^{-}$ & $\mathrm{Ar}$ & $\mathrm{Ar}$ & $\mathrm{Ar}$ & $\mathrm{Ar}$ \\
$\mathrm{B}_{8} \mathrm{C}_{2}$ & $\mathrm{Ar}$ & $\mathrm{Ar}$ & $\mathrm{Ar}$ & $\mathrm{Ar}$ \\
$\mathrm{B}_{8} \mathrm{C}_{2}^{2-}$ & $\mathrm{Ar}$ & $\mathrm{Anti}-\mathrm{Ar}$ & $\mathrm{Ar}$ & $\mathrm{Anti}-\mathrm{Ar}$ \\
$\mathrm{B}_{7} \mathrm{C}_{3}^{-}$ & $\mathrm{Ar}$ & $\mathrm{Anti}-\mathrm{Ar}$ & $\mathrm{Ar}$ & $\mathrm{Anti}-\mathrm{Ar}$ \\
$\mathrm{B}_{11} \mathrm{C}_{5}^{+}$ & $\mathrm{Ar}$ & $\mathrm{Ar}$ & $\mathrm{Ar}$ & $\mathrm{Ar}$ \\
$\mathrm{B}_{11} \mathrm{C}_{5}^{-}$ & $\mathrm{Ar}$ & $\mathrm{Anti-Ar}$ & $\mathrm{Ar}$ \\
\hline
\end{tabular}




\section{References}

${ }^{1}$ Fehlner, T. P.; Halet, J. F.; Saillard, J. Y. Molecular Clusters: A Bridge to Solid-State Chemistry; Cambridge University Press: Cambridge, U.K., 2007

${ }^{2}$ B. T. Tai, N. M. Tam and Nguyen M. T. Chem. Phys. Lett., 2012, 530,71.

${ }^{3}$ B. T. Tai, D. J. Grant, M. T. Nguyen, D. A. Dixon, J. Phys. Chem. A, 2010, 114, 994.

${ }^{4}$ B. T. Tai and M. T. Nguyen, Phys. Chem. Chem. Phys. 2015, 17, 13672.

${ }^{5}$ L. Chen, J. Chem. Phys. 2012, 136, No. 104301.

${ }^{6}$ L. V. Duong, H. T. Pham, N. M. Tam and M. T. Nguyen, Phys. Chem. Chem. Phys., 2014, 16, 19470.

${ }^{7}$ B. T. Tai, N. M Tam and M. T. Nguyen, Theor. Chem. Acc. 2012, 131, 1241

${ }^{8}$ A. P. Sergeeva, I. A. Popov, Z. A. Piazza, W. L. Li, C. Romanescu, L. S. Wang and A. I. Boldyrev, Acc. Chem. Res., 2014, 47, 1349.

${ }^{9}$ T. B. Tai, L. V. Duong, H. T. Pham, D. T. T. Mai and M. T. Nguyen, Chem. Commun. 2014, 50, 1558.

${ }^{10}$ T. B. Tai and M. T. Nguyen, Chem. Commun., 2015, 51, 7677.

${ }^{11}$ W.L. Li, Q. Chen, W. J. Tian, H. Bai, Y. F. Zhao, H. S. Hu, J. Li, H. J. Zhai, S. D. Li and L. S. Wang, J. Am. Chem. Soc., 2014, 136, 12257.

${ }^{12}$ H. T. Pham, L.V. Duong, N. M. Tam, M. P. Pham-Ho and M. T. Nguyen, Chem. Phys. Lett. 2014, 608, 295.

${ }^{13}$ J. T. Muya, H. Ramanantoanina, C. Daul, M. T. Nguyen, G. Gopakumar and A. Ceulemans, Phys. Chem. Chem. Phys., 2013,15, 2829.

${ }^{14}$ D. E. Bean, J. T. Muya, P. W. Fowler, M. T. Nguyen and A. Ceulemans, Phys. Chem. Chem. Phys., 2011,13, 20855.

${ }^{15}$ J. T. Muya, G. Gopakumar, M. T. Nguyen and A. Ceulemans, Phys. Chem. Chem. Phys., 2011,13, 7524.

${ }^{16}$ J. T. Muya, T. Sato, M. T. Nguyen and A. Ceulemans, Chem. Phys. Letts., 2012, 543, 111.

${ }^{17}$ A. Ceulemans, J. T. Muya, G. Gopakumar and M.T. Nguyen, Chem. Phys. Lett., 2008, 461, 226.

${ }^{18}$ G. Gopakumar, M. T. Nguyen and A. Ceulemans, Chem. Phys. Lett. 2008, 450, 175.

${ }^{19}$ H. J. Zhai, Y. F. Zhao, W. L. Li, Q. Chen, H. Bai, H. S. Hu, Z. A. Piazza, W. J. Tian, H. G. Lu, Y. B. Wu, Y. W. Mu, G. F. Wei, Z. P. Liu, J. Li, S. D. Li and L. S. Wang, Nat. Chem., 2014, 6,727.

${ }^{20}$ T. B. Tai and M. T. Nguyen, Nanoscale, 2015, 7, 3316.

${ }^{21}$ T. B. Tai and M. T. Nguyen, Chem. Commun. 2016, 51, 1653. 
${ }^{22}$ T. B. Tai, S. U. Lee and M. T. Nguyen, Phys. Chem. Chem. Phys. 2016, 18, (under review).

${ }^{23}$ T. B. Tai, R. W. A. Havenith, J. L. Teunissen, A. R. Dok, S. D. Hallaert, M. T. Nguyen and A. Ceulemans, Inorg. Chem., 2013, 52, 10595.

${ }^{24}$ T. B. Tai, V. T. T. Huong and M. T. Nguyen, Top. Heterocyclic. Chem., 2014, 38, 161.

${ }^{25}$ H. T. Pham, D. V. Long and M. T. Nguyen, J. Phys. Chem. C, 2014, 118, 24181.

${ }^{26}$ J. I. Aihara, H. Kanno and T. Ishida, J. Am. Chem. Soc., 2005, 127,13324.

${ }^{27}$ Y. D. Zubarev and I. A. Boldyrev, J. Comput. Chem., 2007, 28, 251.

${ }^{28}$ L. Rincon, R. Almeida, J. E. Alvarellos, D. G. Aldea, A. Hasmy and C. Gonzalez, Dalton Trans., 2009, 3328.

${ }^{29}$ R. W. A. Havenith, P. W. Fowler and E. Steiner, Chem. Eur. J. 2002, 8, 1086.

${ }^{30}$ F. D. Proft, P. W. Fowler, R. W. A. Havenith, P. v. R. Schleyer, G. V. Lier and P. Geerlings, Chem. Eur. J.,2004, 10, 940.

${ }^{31}$ Z. Badri, S. Pathak, H. Fliegl, P. R. Ranjbar, R. Bast, R. Marek,C. F. Nejad and K. Ruud, J. Chem. Theory Comput., 2013, 9, 4789.

32 J. M. Mercero, A. I. Boldyrev, G. Merino and J. M. Ugalde, Chem. Soc. Rev., 2015, 44, 6519.

${ }^{33}$ P. W. Fowler and A. Soncini, Phys. Chem. Chem. Phys., 2011,13, 20637.

${ }^{34}$ A. S. Matias, R. W. A. Havenith, M. Alcami and A. Ceulemans, Phys. Chem. Chem. Phys. 2015, 17, in press.

${ }^{35}$ L. M. Wang, W. Huang, B. B. Averkiev, A. I. Boldyrev and L. S. Wang, Angew. Chem. Int. Ed. 2007, 46, 4550.

${ }^{36}$ B. B. Averkiev, D. Y. Zubarev, L. M. Wang, W. Huang, L. S. Wang and A. I. Boldyrev, J. Am. Chem. Soc. 2008, 130, 9248 .

${ }^{37}$ T. R. Galeev, W. L. Li, C. Romanescu, I. Černušák, L. S. Wang and A. I. Boldyrev, J. Chem. Phys.,2012, 137, 234306.

${ }^{38}$ J. Hou, Q. Duan, J. Quin, X. Shen, J. Zhao, Q. Liang, D. Jiang and S. Gao, Phys. Chem. Chem. Phys., 2015, 17, 9644

${ }^{39}$ L. F. Li, C. Xu, B. K. Jin and L. J. Cheng, J. Chem. Phys., 2013, 139, 174310.

${ }^{40}$ H. L. Yu, R. L. Sang and Y. Y. Wu, J. Phys. Chem. A, 2009, 113, 3382.

${ }^{41}$ J. J. T. Vega, A. V. Espinal, M. J. Beltran, L. Ruiz, R. Islas and W. Tiznado, Phys. Chem. Chem. Phys., 2015,17, 19602.

${ }^{42}$ J. M. Tao, J. P. Perdew, V. N. Staroverov and G. E. Scuseria, Phys. Rev. Lett. 2003, 91, 146401. 
${ }^{43}$ M.J. Frisch, H. B. Schlegel, G. E. Scuseria, M. A. Robb, J. R. Cheeseman, J. A. Montgomery, T. Vreven, K. N. Kudin, J. C. Burant, J. Millam, J. et al., Gaussian 09 Revision: A.01; Gaussian, Inc.: Wallingford, CT, 2009.

${ }^{44}$ R. Zanasi, J. Chem. Phys., 1996, 105, 1460.

${ }^{45}$ P. Lazzeretti, M. Malagoli and R. Zanasi, Chem. Phys. Lett.,1994, 220, 299.

${ }^{46}$ E. Steiner and P. W. Fowler, J. Phys. Chem. A, 2001, 105, 9553.

${ }^{47}$ T. Keith and R. F. W. Bader, Chem. Phys. Lett., 1993, 210, 223.

${ }^{48}$ P. Lazzeretti, M. Malagoli and R. Zanasi, SYSMO package, Technical Report "Sistemi Informatici e Calcolo Parallelo”, CNR Italy (1991). Research Report number 1/67. Additional routines by P. W. Fowler, E. Steiner, R. W. A. Havenith and A. Soncini.

${ }^{49}$ R. W. A. Havenith and P. W. Fowler, Chem. Phys. Lett., 2007, 449, 347.

${ }^{50}$ M. F. Guest, et al., Gamess-UK, Mol. Phys., 2005, 103, 719.

${ }^{51}$ J. Jin, G. Wang, M. Zhou, D. M. Andrada, M. Hermann, and Gernot Frenking, Angew. Chem. Int. Ed. 2016, 55, 2078.

${ }^{52}$ F. Feixas, J. O. C. J. Halla, E. Matito, J. Poater and Miquel Solà, J. Chem. Theory Comput. $2010,6,1118$.

53 N. M. Tam, H. T. Pham, M. T. Nguyen, Chem. Phys. Lett., 2014, 608, 255.

54 P.W. Fowler, R.W.A. Havenith and E. Steiner, Chem. Phys. Lett. 2000, 34285.

${ }^{55}$ P.W. Fowler, R.W.A. Havenith and E. Steiner, Chem. Phys. Lett. 2002, 359, 530.

${ }^{56}$ R. W. A. Havenith, P. W. Fowler and E. Steiner, Chem. Eur. J. 2002, 8, 1068.

${ }^{57}$ B. Kiran, G. G. Kumar, M. T. Nguyen, A. K. Kandalam and P. Jena, Inorg. Chem., 2009, 48, 9965.

${ }^{58}$ D. Moreno, S. Pan, L. L. Zeonjuk, R. Islas, E. Osorio, G. M. Guajardo, P. K. Chattaraj, T. Heine and G. Merino, Chem. Commun., 2014, 50, 8140.

${ }^{59}$ B. T. Tai, A. Ceulemans and M. T. Nguyen, Chem. Eur. J. 2012,18, 4510.

${ }^{60}$ T. B. Tai, R. W. A. Havenith, J. L. Teunissen, A. R. Dok, S. D. Hallaert, M. T. Nguyen and A. Ceulemans, Inorg. Chem. 2013, 52, 10595.

${ }^{61}$ B. B. Averkiev, L. M. Wang, W. Huang, L. S. Wang and A. I. Boldyrev, Phys. Chem. Chem. Phys. 2009, 11, 9840.

${ }^{62}$ S. Erhardt, G. Frenking, Z. Chen and Paul v. R. Schleyer, Angew. Chem. Int. Ed. 2005, 44, 1078. 